\title{
Brain oximetry is not a good monitor on reducing neurological complications after cardiac surgery
}

\author{
Seyed Mohammadreza Amouzegar Zavareh*, Hasan Araghizade**, \\ Nahid Eskandari*** and Marzieh Lak**
}

\begin{tabular}{l}
\hline \\
\hline *Atrosclrose Research Center, \\
Baqiyatallah University of Medical \\
Sciences, Tehran, Iran \\
**Truma Research Center, \\
Baqiyatallah University of Medical \\
Sciences, Tehran, Iran \\
***Department of Immunology, \\
Faculty of Medicine, Isfahan \\
University of Medical Sciences, \\
Isfahan, Iran \\
Correspondence: \\
Marzieh Lak \\
Truma Research Center, Baqiyatallah \\
University of Medical Sciences \\
Tehran, Iran \\
Email: marziehlak@yahoo.com \\
ORCID ID: orcid.org/0000-0003- \\
3498-4653
\end{tabular}

Date of first submission, October 24, 2018

Date of final revised submission, May 24, 2019

Date of acceptance, June 17, 2019

This open access article is distributed under a Creative Commons AttributionNon Commercial-Share Alike 4.0 International License

Cite this article as: Zavareh SMA, Hasan Araghizade H, Eskandari N, et al. Brain oximetry is not a good monitor on reducing neurological complications after cardiac surgery. Univ Med 2019; 38:81-9. doi: 10.18051/UnivMed 2018.v38.81-89

\section{BACKGROUND}

Cerebral deoxygenation is related to several adverse systemic consequences. We aimed to assess the effect of noninvasive monitoring of cerebral oxygenation on reducing neurological complications after cardiac surgery.

\section{METHODS}

In this randomized clinical trial, subjects were randomized into two groups: intervention group (111 subjects with monitoring of cerebral oximetry) and control group (112 subjects without any monitoring of cerebral oximetry). Monitoring of regional cerebral oxygen saturation $(\mathrm{rScO} 2)$ was performed in the intervention group without any monitoring of cerebral oxygenation. The $\mathrm{rScO} 2$ was not recorded in the control group and no specific treatments were employed. Any neurological complications such as hallucinations, delirium, stroke, and length of stay in ICU after surgery were recorded. Apvalue less than 0.05 was used as a cut-off for statistical significance.

\section{RESULTS}

After surgery, in the intervention group one $(1 / 111=0.09 \%)$ patient suffered from stroke and one patient had delirium, while in the control group three patients had stroke and three $(3 / 112=2.6 \%)$ had delirium. There was no significant difference between the two groups regarding complications $(\mathrm{p}=0.527)$. The length of stay in ICU was $3.49 \pm 0.96$ days in the case group and $3.40 \pm 0.80$ days in the control group and there was no significant difference in the two groups $(\mathrm{p}=0.477)$.

\section{CONCLUSION}

Monitoring of $\mathrm{rScO} 2$ does not seem to be a good monitor for brain oxygenation. Further studies are needed to judge the usefulness of $\mathrm{rScO} 2$ for monitoring brain oxygenation.

Keywords: Regional cerebral oxygen saturation, cardiac surgery, neurological complications 


\section{INTRODUCTION}

Advancing age and associated diseases in patients undergoing cardiac surgery raise postoperative neurological complications such as stroke and other adverse perioperative outcomes. $^{(1-3)}$ The prevalence of cognitive impairment after coronary artery bypass graft (CABG) surgery of more than $50 \%$, as well as the relationship of hypoxia of the brain with nervous disorders, increased length of stay in ICU and hospital stay are described in several studies. ${ }^{(4,5)}$ During cardiopulmonary bypass the blood supply to the brain is impaired, due to cerebral auto-regulatory dysfunction, arterial embolism, cerebral venous obstruction, technical problems, as well as the patient's underlying disease (carotid stenosis). ${ }^{(6,7)}$

Cardiac surgery under cardiopulmonary bypass leads to an imbalance in brain oxygenation and oxygen consumption. ${ }^{(8-10)}$ Reducing oxygenation of the brain is associated with neuropsychiatric disorders after surgery (11-13) Although the technology of transcranial nearinfrared spectroscopy (NIRS) was introduced 25 years ago for the measurement of cerebral oxygen saturation, until recently there was little interest in using it during surgery. ${ }^{(14)}$ Brain oximetry is a non-invasive method for monitoring brain tissue oxygenation, which is probably the benchmark for total brain oxygenation. ${ }^{(15)}$ In a review article, Zheng et al. ${ }^{(16)}$ concluded that at present, studies have not been able to prove that intervention to modify the regional cerebral $\mathrm{O}_{2}$ saturation leads to a reduction in post-operative neurological complications. There is no universal definition of brain oxygen desaturation as abnormal findings. In various reviewed studies, both the relative reduction of brain oxygen saturation from baseline, and its absolute reduction (e.g., less than 50\%) were used. ${ }^{(17-19)}$ Oximetry of the brain may be valuable in heart surgery in detecting abnormality in cerebral blood flow and its correction. In this study, we aimed to assess the effect of noninvasive monitoring of cerebral oxygenation on reducing neurological complications after cardiac surgery.

\section{METHODS}

\section{Research design}

A randomized clinical trial was carried out on 223 patients who underwent cardiac surgery with cardiopulmonary bypass (CPB) pump in Tehran, Iran, between March 2017 and October 2018.

\section{Research subjects}

Using a computer-generated randomization list, patients were divided into two groups: intervention group (111 patients with monitoring of cerebral oximetry), and control group (112 without any monitoring of cerebral oximetry).

\section{Sample size determination}

The calculation of sample size was based on a presumed effect size of 0.4 , a statistical power of $80 \%$, and a type I error of $5 \%$, which yielded 100 patients per group. However, for more confidence at least 112 subjects per group was considered in this study.

\section{Intervention}

In the intervention group, before anesthesia patients had bilateral oximetry probe, and regional brain oxygenation were recorded; during the operation, $\mathrm{rScO}_{2}$ was continuously monitored and recorded. If the absolute threshold of $\mathrm{rScO}_{2}$ was less than $50 \%$, interventions were performed to maintain $\mathrm{rScO}_{2}$ over $50 \%$. The $\mathrm{rScO}_{2}$ was not recorded in the control group and no specific treatments were employed. Before induction of anesthesia and endotracheal intubation, all patients in the case group had INVOS cerebral oximeter sensors (INVOS 5100C; Somanetics Corp, Troy, MI) placed bilaterally on the forehead and baseline regional cerebral oxygen saturation values were measured.

Performing of cerebral oximetry is not compulsory and using it is not routine in our 
hospital due to its cost. This is the reason why cerebral oximetry was not performed in the control group.

Induction of anesthesia was performed using fentanyl ( $7 \mu \mathrm{g} / \mathrm{kg})$, diazepam $(0.15 \mathrm{mg} / \mathrm{kg})$, and atracurium $(0.5 \mathrm{mg} / \mathrm{kg})$. After intubation for maintenance, anesthesia comprised of fentanyl $(0.07 \mu \mathrm{g} / \mathrm{kg} / \mathrm{min})$, midazolam $(0.5 \mu \mathrm{g} / \mathrm{kg} / \mathrm{min})$, atracurium $(0.8 \mu \mathrm{g} / \mathrm{kg} / \mathrm{min})$ and, if necessary, propofol infusion $(20-200 \mathrm{mg} / \mathrm{h})$ was used. Central venous pressure (CVP) was recorded in the right internal jugular vein. Patient's vital signs were recorded every five minutes, including blood pressure (BP) by the invasive method, pulse rate (PR), core temperature by the nasal method, oxygen saturation with pulse oximetry $\left(\mathrm{SPO}_{2}\right)$ and end-tidal $\mathrm{CO}_{2}(\mathrm{ET} \mathrm{CO})$ and CVP.

Also, we maintained systolic blood pressure at 100 to $110 \mathrm{~mm} \mathrm{Hg}$ by nitroglycerin (TNG) and inotrope. Heparin was injected after sternotomy and discharging of the internal thoracic artery and saphenous vein. Activated clotting time (ACT) was checked three to five minutes after injection of heparin. If the ACT was equal to or more than 480 seconds, we connected the patient to CPB pumps (pump type was Stockert SIII with head type roller pump, and prime fluid included: mannitol, Ringer, heparin, bicarbonate, voluven and transamine.

The temperature of the patients was kept at around $32-34^{\circ} \mathrm{C}$ during the CPB pump. Blood flow rate of CPB pump was calculated based on the body surface area (BSA) $(2.4 \mathrm{l} / \mathrm{min} /$ BSA). By changing blood flow rate of CPB pump and using noradrenaline or TNG, mean arterial pressure during cardiopulmonary bypass was maintained between 50 to $80 \mathrm{mmHg}$. $\mathrm{PaCO} 2$ was maintained between $35-45 \mathrm{mmHg}$ with changing of oxygen flow of CPB pump and monitored with measurement of arterial blood gases. Arterial blood gases (ABG) were determined after installing the arterial line, after induction of anesthesia, after starting of CPB pump, half an hour after the CPB pump, at end of CPB and each time that there was a decrease in the oxygen saturation of the boundary. An absolute threshold of brain saturation (e.g., less than $50 \%$ ) was used in the various studies. ${ }^{(17)}$ Interventions that occurred during the loss of $\mathrm{rScO}_{2}$ below $50 \%$, included increasing partial pressure of carbon dioxide $\left(\mathrm{PaCO}_{2}\right)$ to $45 \mathrm{mmHg}$, increasing blood pressure by increasing blood flow pump, use of inotropes, and lowering oxygen consumption of the brain using barbiturates and repositioning the patient's head. Percentile of desaturation below $50 \%$ and minutes of desaturation were recorded.

Patients were separated from the CPB pump after establishing satisfactory conditions such as hematocrit (Hct) equal to or more than $22 \%$, normal electrolytes and acid-base status. We started protamine sulfate for the reversal of heparin. After the operation, patients were transferred to the open heart intensive care unit. Weaning and extubation were administered according to the standards of the open heart intensive care unit, such as complete consciousness, hemodynamic stability, appropriate drainage volume and normal chest X-ray.

All patients had elective surgery and emergency patients have not been investigated. Intramuscular morphine (five $\mathrm{mg}$ ) and one $\mathrm{mg}$ oral lorazepam one hour preoperative were administered to each patient. We conducted the patients to the operating room with standard monitoring. Vital signs and invasive blood pressure monitoring by the left radial artery were recorded.

\section{Measurements}

The serum fasting blood sugar (FBS), blood urea nitrogen (BUN), creatinine, sodium, potassium, $\mathrm{Hb}$, and $\mathrm{Hct}$ of each patient were measured preoperatively. Patients with a history of psychological disorder as well as patients who were taking psychiatric drugs were excluded. Any neurological side effects such as hallucinations, delirium, and stroke and so on up to length of stay in ICU after surgery were recorded. 


\section{Statistical analysis}

Data was presented as mean, SD, frequency and percentage. The normality of the data was assessed using the KolmogorovSmirnov test. Independent t-test was used for comparison of variables with normal distribution between the two groups. For the quantity variables with non-normal distribution, the Mann Whitney test was used. Also, qualitative data were analyzed by Chi-square and Fisher Exact test depending on circumstance. SPSS version 17 software was used to analyze findings. The p-value less than 0.05 was considered statistically significant.

\section{Ethical clearance}

This study was registered in the Iranian Registry of Clinical Trials under no. IRCT20161022030421N2 cod. The protocol of the study was confirmed by the ethics committee of Baqiyatallah University of Medical Sciences and informed consent was obtained from each patient.

\section{RESULTS}

Two hundred thirty three patients were screened for inclusion in the study. No one was excluded, and a total of 233 patients was randomized into the intervention group (111 patients) and 112 patients into the control group. The primary analysis included all randomized patients (Figure 1). They were followed up for 3-4 days post-surgery.

At base line age, gender and type of surgery were similar between the two groups (Table 1). Also, there was no statistically significant difference between the groups based on preoperative clinical factors and carotid artery stenosis (Table 1 and Table 2). Comparison of the two groups in terms of intraoperative clinical factors indicated that there was no significant difference between the two groups in terms of CPB time and cross-clamp time (Table 2). In the intervention group, one patient suffered from a stroke (a man 61 years old with a history of diabetes, hypertension, smoker and opium

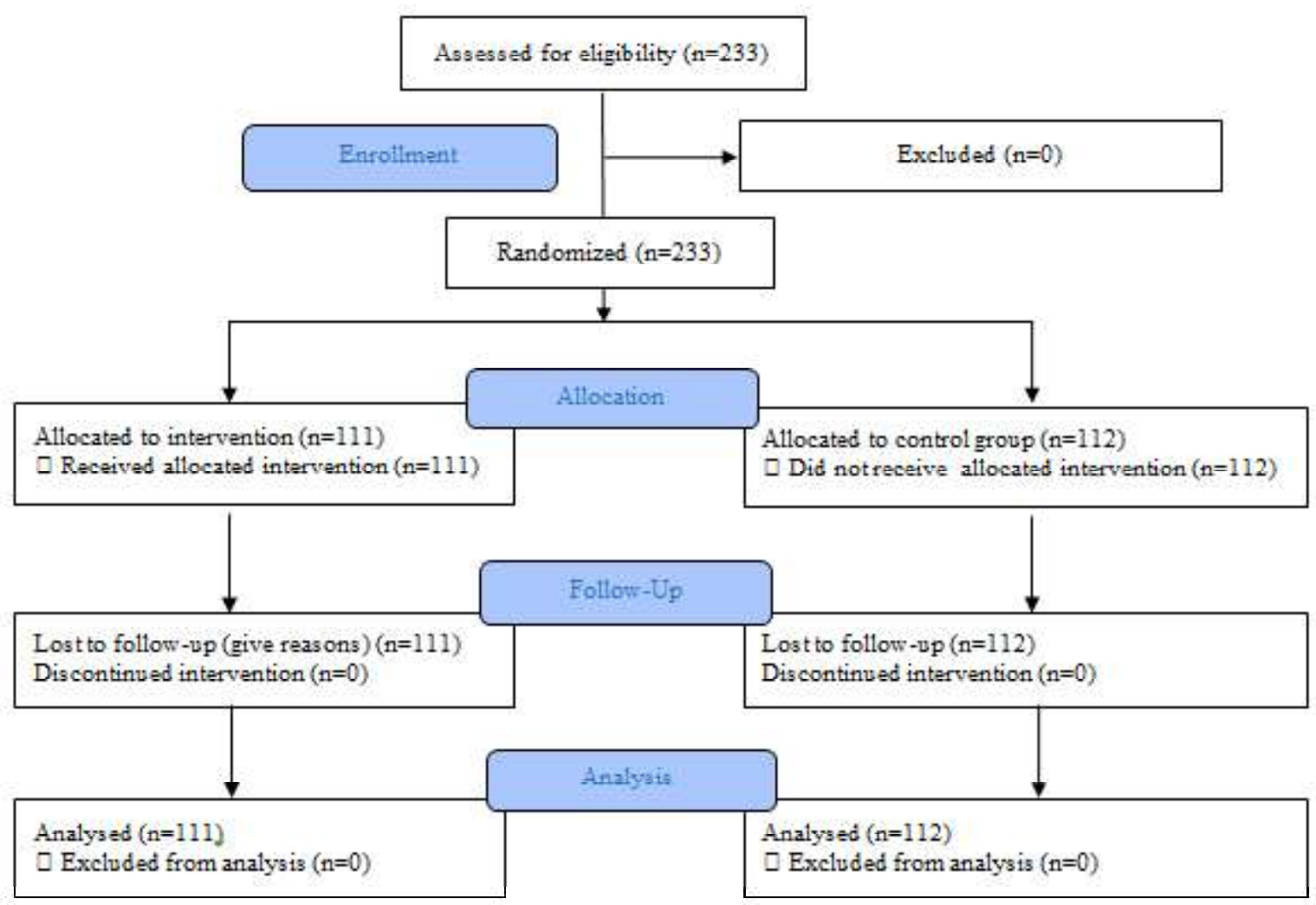

Figure 1. The flow diagram of the subjects 
Table 1. Demographics, ejection fraction, type of surgery and pre-operative clinical factors by treatment groups at base line

\begin{tabular}{lccc}
\hline & $\begin{array}{c}\text { Intervention (n=111) } \\
\text { Mean (SD) }\end{array}$ & $\begin{array}{c}\text { Control (n=112) } \\
\text { Mean(SD) }\end{array}$ & p value \\
\hline Age (years) & $62.02(10.34)$ & $59.98(11.19)$ & 0.171 \\
Ejection fraction ( \%) & $45.95(9.24)$ & $46.71(8.15)$ & 0.109 \\
Sex & $\mathrm{n}(\%)$ & $\mathrm{n}(\%)$ & \\
$\quad$ Female & $32(28.8)$ & $28(25.2)$ & $0.546^{2}$ \\
$\quad$ Male & $79(71.2)$ & $83(74.8)$ & \\
Type of surgery & & & \\
CABG & $92(86.0)$ & $92(83.6)$ & $0.631^{2}$ \\
MVR & $19(17.8)$ & $15(13.5)$ & $0.388^{2}$ \\
AVR & $14(13.1)$ & $19(17.1)$ & $0.406^{2}$ \\
Risk Factors & & & \\
$\quad$ Hypertension & $73(65.8)$ & $61(54.5)$ & $0.101^{2}$ \\
$\quad$ Hyperlipidemia & $58(52.7)$ & $46(41.1)$ & $0.106^{2}$ \\
$\quad$ Diabetes mellitus & $48(43.2)$ & $40(35.7)$ & $0.250^{2}$ \\
Thyroid dysfunction & $1(1)$ & $2(1.8)$ & $0.503^{3}$ \\
Kidney dysfunction & $8(7.2)$ & $8(7.1)$ & $0.985^{2}$ \\
Transient ischemic attack & $3(2.7)$ & $2(1.8)$ & $0.683^{3}$ \\
Cerebrovascular accident & $11(9.9)$ & $10(8.9)$ & $0.802^{3}$ \\
Cigarette smoking & $11(9.9)$ & $5(4.5)$ & $0.115^{2}$ \\
Pulmonary dysfunction & $11(9.9)$ & $10(8.9)$ & $0.802^{3}$ \\
Opioid addiction & $21(18.9)$ & $15(13.4)$ & $0.262^{2}$ \\
Myocardial infarction & $12(10.8)$ & $8(7.1)$ & $0.338^{3}$ \\
Chemical lung injury & $1(0.9)$ & $2(1.8)$ & $0.503^{3}$ \\
\hline
\end{tabular}

1: Independent Sample T-Test 2: Pearson Chi-Square Test $\quad 3:$ Fisher Exact Test

addiction. In the control group there were three ICU was $3.49 \pm 0.96$ days in the intervention patients with stroke and three patients with group and $3.40 \pm 0.80$ days in the control group delirium. There was no significant difference and there was no between difference between between the two groups. The length of stay in the two groups ( $\mathrm{p}=0.447)$ (Table 2).

Table 2. Comparison of the two groups in terms of the number of patients with carotid artery stenosis, neurological complications after surgery, length of stay in ICU

\begin{tabular}{cccc}
\hline & $\begin{array}{c}\text { Intervention (n=111) } \\
\mathbf{n ~ ( \% )}\end{array}$ & $\begin{array}{c}\text { Control (n=112) } \\
\mathbf{n}(\%)\end{array}$ & p value \\
\hline Carotid & $43(38.7)$ & $40(35.7)$ & $0.640^{1}$ \\
CVA & $1(0.9)$ & $3(2.7)$ & $0.622^{2}$ \\
Delirium & $1(0.9)$ & $3(2.7)$ & $0.622^{2}$ \\
Neurological & $2(3.6)$ & $6(5.4)$ & $0.527^{2}$ \\
& Mean (SD) & Mean (SD) & \\
Length of stay in ICU (days) & $3.49(0.96)$ & $3.40(0.80)$ & $0.477^{3}$ \\
CPB & $56.95(17.92)$ & $59.85(24.89)$ & $0.326^{4}$ \\
CCt & $45.90(16.23)$ & $40.88(20.36)$ & $0.058^{4}$ \\
\hline
\end{tabular}

1: Pearson Chi-Square Test, 2: Fisher Exact Test, 3: Mann Whitney Test, 4: Independent Sample T-Test ICU : intensive care unit; CVA :cerebro vascular accident; CPB : cardiopulmonary bypass ; CCt: Cross Clamp time 
Table 3. The average time(minutes) of $\mathrm{rScO}_{2}$ less than 50 in different stages in intervention group

\begin{tabular}{cccc}
\hline & & Number of patients & Mean (SD) (min) \\
\hline \multirow{2}{*}{ Pre Pump } & Right & 30 & $26.67(16.05)$ \\
& Left & 23 & $26.30(17.14)$ \\
\multirow{2}{*}{ On Pump } & Right & 52 & $26.35(20.32)$ \\
& Left & 49 & $27.04(21.29)$ \\
\multirow{2}{*}{ Post Pump } & Right & 23 & $23.48(22.38)$ \\
& Left & 22 & $20.23(22.55)$ \\
\hline
\end{tabular}

In the intervention group, 73 patients had at least one stage $\mathrm{rScO} 2$ less than $50 \%$ in one side, 56 patients had at least five minutes of $\mathrm{rScO} 2$ less than $50 \%$ in the left side and 57 patients in the right side. A total of 38 patients had never $\mathrm{rScO} 2$ of less than $50 \%$. Table 3 shows the average time of $\mathrm{rScO} 2$ less than $50 \%$ in different stages. The cerebral oxygen desaturation at different stages follows the following steps; pre-pump: 45 minutes in right side and 40 minutes in left side, in pump: 15 minutes in right side and 20 minutes in left side, post pump: 20 minutes in right side and 10 minutes in left side (Table 4).

\section{DISCUSSION}

Neurological problems of cardiac surgery have a huge effect on patient outcomes. In adding to a decrease in the prevalence of

Table 4. The number of patients and duration of cerebral oxygen desaturation at different stages

\begin{tabular}{|c|c|c|c|c|c|c|}
\hline \multirow{2}{*}{$\begin{array}{c}\text { Duration of } \\
\mathrm{rScO}_{2}<50\end{array}$} & \multicolumn{2}{|c|}{ Pre Pump n (\%) } & \multicolumn{2}{|c|}{ On Pump n (\%) } & \multicolumn{2}{|c|}{ Post Pump n (\%) } \\
\hline & Right & Left & Right & Left & Right & Left \\
\hline $0 \mathrm{~min}$ & $81(73)$ & $88(79.3)$ & $59(53.2)$ & $62(55.9)$ & $87(78.4)$ & $88(79.3)$ \\
\hline $5 \mathrm{~min}$ & $3(2.7)$ & $1(0.9)$ & $10(9)$ & $9(8.1)$ & $5(4.5)$ & $6(5.4)$ \\
\hline $10 \mathrm{~min}$ & $4(3.6)$ & $7(6.3)$ & $6(5.4)$ & $6(5.4)$ & $3(2.7)$ & $3(2.7)$ \\
\hline $15 \mathrm{~min}$ & $2(1.8)$ & $3(2.7)$ & $7(6.3)$ & $6(5.4)$ & $2(1.8)$ & $3(2.7)$ \\
\hline $20 \mathrm{~min}$ & $4(3.6)$ & $1(0.9)$ & $4(3.6)$ & $7(6.3)$ & $4(3.6)$ & $5(4.5)$ \\
\hline $25 \mathrm{~min}$ & $5(4.5)$ & 0 & $5(4.5)$ & $2(1.8)$ & $5(4.5)$ & $1(0.9)$ \\
\hline $30 \mathrm{~min}$ & $3(2.7)$ & $3(2.7)$ & & $3(2.7)$ & 0 & $2(1.8)$ \\
\hline $35 \mathrm{~min}$ & $2(1.8)$ & $1(0.9)$ & $6(5.4)$ & $1(0.9)$ & 0 & 0 \\
\hline $40 \mathrm{~min}$ & $1(0.9)$ & $1(0.9)$ & $5(4.5)$ & $2(1.8)$ & 0 & $1(0.9)$ \\
\hline $45 \mathrm{~min}$ & $3(2.7)$ & $1(0.9)$ & $2(1.8)$ & $4(3.6)$ & $2(1.8)$ & 0 \\
\hline $50 \mathrm{~min}$ & $1(0.9)$ & $1(0.9)$ & $2(1.8)$ & $3(2.7)$ & 0 & 0 \\
\hline $55 \mathrm{~min}$ & 0 & $1(0.9)$ & $2(1.8)$ & $3(2.7)$ & $1(0.9)$ & 0 \\
\hline $60 \mathrm{~min}$ & $1(0.9)$ & 0 & 0 & 0 & 0 & 0 \\
\hline $65 \mathrm{~min}$ & $1(0.9)$ & 0 & 0 & 0 & 0 & 0 \\
\hline $70 \mathrm{~min}$ & 0 & 0 & $1(0.9)$ & $1(0.9)$ & 0 & 0 \\
\hline $75 \mathrm{~min}$ & 0 & 0 & 0 & 0 & 0 & 0 \\
\hline $80 \mathrm{~min}$ & 0 & 0 & 0 & 0 & 0 & 0 \\
\hline $85 \mathrm{~min}$ & 0 & 0 & 0 & 0 & 0 & 0 \\
\hline $90 \mathrm{~min}$ & 0 & 0 & 0 & $1(0.9)$ & 0 & 0 \\
\hline $95 \mathrm{~min}$ & 0 & 0 & $1(0.9)$ & $1(0.9)$ & 0 & 0 \\
\hline $100 \mathrm{~min}$ & 0 & 0 & 0 & 0 & 0 & 0 \\
\hline $105 \mathrm{~min}$ & 0 & 0 & 0 & 0 & $1(0.9)$ & 0 \\
\hline $110 \mathrm{~min}$ & 0 & 0 & 0 & 0 & 0 & $1(0.9)$ \\
\hline
\end{tabular}


neurological damage and length of hospital stay, intra-operative use of cerebral oximetry monitoring has been accompanied by early detection of potentially severe brain damage demanding fast mediation. ${ }^{(18,19)}$

There was no significant difference between the two groups regarding age, sex, type of surgery, preoperative clinical factors, carotid artery stenosis, CPB time and crossclamp time. In terms of neurological complications after surgery, in the intervention group, one patient suffered from a stroke and one patient had delirium, while in the control group there were three patients with stroke and three patients with delirium, but there was no significant difference between the two groups. Although in the case group 73 patients had brain oxygen desaturation, neurological complications were rare. There was no significant difference between the two groups in terms of the length of stay in ICU.

In contrast to this study, Parnia et al.(20) indicated that in patients who had an in-hospital cardiac arrest, it was proved that monitoring of brain oxygen saturation could predict the return of spontaneous circulation (ROSC). They also demonstrated that patients with ROSC had oxygen saturation above $30 \%$ for more than $50 \%$ of the duration of cardiac arrest, while those who died had oxygen saturation below $30 \%$ for more than $50 \%$ of their cardiac arrest duration. In addition, other research performed brain oximetry in patients who went to the intensive care unit after resuscitation from cardiac arrest. They did not find significant differences in the oximetry of the brain in surviving patients compared to those who died during 24-48 hours post resuscitation. ${ }^{(21)}$

In a study on patients undergoing cardiac surgery with CPB pump, it was concluded that patients who had $\mathrm{rScO}_{2}$ drops had post-operative neuropsychological disorders. But whether intervention to maintain $\mathrm{rScO}_{2}$ can prevent neuropsychological disorders, has not been investigated. ${ }^{(22)}$ Moreover, the effect of brain oximetry on neurocognitive function of patients after coronary surgery is that the cognitive outcome in the oximetry group is significantly better than that in the control group. ${ }^{(23)}$

In post hoc analysis in diabetic patients, Murkin et al. ${ }^{(1)}$ concluded that monitoring and maintaining oxygen saturation in diabetic patients reduce postoperative complications and the length of stay in the ICU.

Slater et al. ${ }^{(4)}$ divided 265 patients who underwent coronary artery bypass grafting to control and intervention groups. In the intervention group, if $\mathrm{rScO}_{2}$ dropped $20 \%$ from the base, intervention was performed to maintain it. In the control group, $\mathrm{rScO}_{2}$ was recorded, but there was no intervention to maintain it. The investigators observed that patients with an $\mathrm{rScO}_{2}$ desaturation score above $3000 \%$-second had a higher risk of neurological complications after surgery, and longer hospitalization periods.

Subramanian et al. ${ }^{(3)}$ in a multicenter research showed that $50 \%$ to $75 \%$ of cardiac surgery patients have one or more $\mathrm{rScO}_{2}$ desaturations while undergoing $\mathrm{CPB}$. Approximately $10 \%$ of desaturation events were not recognized by clinicians, recommending that suitable alert systems should be implemented to warn clinicians of such happenings.

We tried to maintain pre-pump systolic blood pressure between 100 to $110 \mathrm{~mm} \mathrm{Hg}$ by using TNG and inotrope and during cardiopulmonary bypass by changing rate of CPB pump blood flow, and using noradrenaline or TNG to maintain mean arterial pressure at 50 to $80 \mathrm{~mm} \mathrm{Hg}$.

During the operation, patients in the case group had continuous monitoring of the $\mathrm{rScO}_{2}$ during the entire period of the operation. If the absolute threshold of $\mathrm{rScO}_{2}$ was less than $50 \%$, intervention was performed to maintain regional $\mathrm{rScO}_{2}$ at, or above, the baseline value. As shown in Tables 2 and 3, the intervention failed to quickly reach the brain's $\mathrm{rScO}_{2}$ of $50 \%$. The monitor $\mathrm{rScO}_{2}$ does not seem to be a good monitor for brain oxygenation; instead, maintaining hemodynamics in the various stages of the operation is more important in reducing neurological complications. 
The major limitation of this study was that we did not restore hemodynamic stability with the use of vasoactive drugs, when we could have prevented neurological complications in both groups. The use of $\mathrm{rScO}_{2}$ has a high cost for medical service. Although our findings did not show any differences between the two groups, more studies are required to reach conclusions on the application of $\mathrm{rScO}_{2}$ for monitoring brain oxygenation.

\section{CONCLUSION}

The monitor $\mathrm{rScO}_{2}$ does not seem to be a good monitor for brain oxygenation. Further studies are needed to judge the usefulness of $\mathrm{rScO}_{2}$ for monitoring brain oxygenation.

\section{CONFLICT OF INTEREST}

The authors declare there is not conflict of interest.

\section{ACKNOWLEDGEMENT}

We thank the staff of Trauma Research Center of Baqiyatallah University of Medical Sciences for their kind cooperation in this research.

\section{CONTRIBUTORS}

SMAZ and ML contributed to the study concept, design, analysis and interpretation of data. HA and ML contributed to drafting of the manuscript. All authors have read and approved the final manuscript.

\section{REFERENCES}

1. Murkin JM, Adams SJ, Pardy E, et al. Monitoring brain oxygen saturation during coronary bypass surgery improves outcomes in diabetic patients: a post hoc analysis. Heart Surg Forum 2011;14:E16. doi: 10.1532/HSF98.20101065.

2. Deschamps A, Hall R, Grocott H, et al. Cerebral oximetry monitoring to maintain normal cerebral oxygen saturation during high-risk cardiac surgery: a randomized controlled feasibility trial.
Anesthesiology 2016;124:826-36. doi: 10.1097/ ALN.0000000000001029.

3. Subramanian B, Nyman C, Fritock M, et al. A multicenter pilot study assessing regional cerebral oxygen desaturation frequency during cardiopulmonary bypass and responsiveness to an intervention algorithm. Anesth Analg 2016;122: 1786-93. doi: 10.1213/ANE.0000000000001275.

4. Slater JP, Guarino T, Stack J, et al. Cerebral oxygen desaturation predicts cognitive decline and longer hospital stay after cardiac surgery. Ann Thor Surg 2009;87:36-44. doi: 10.1016/j.athoracsur. 2008.08.070.

5. Green DW, Kunst G. Cerebral oximetry and its role in adult cardiac, non cardiac surgery and resuscitation from cardiac arrest. Anaesthesia 2017;72:48-57. doi: 10.1111/anae.13740.

6. Tovedal T, Thelin S, Lennmyr F. Cerebral oxygen saturation during pulsatile and non-pulsatile cardiopulmonary bypass in patients with carotid stenosis. Perfusion 2016;31:72-7. doi: 10.1177/ 0267659115586280.

7. Aktuerk D, Mishra PK, Luckraz H, et al. Cerebral oxygenation monitoring in patients with bilateral carotid stenosis undergoing urgent cardiac surgery: observational case series. Ann Card Anaesth 2016;19:59-62.

8. Scheeren TW, Kuizenga MH, Maurer H, et al. Electroencephalography and brain oxygenation monitoring in the perioperative period. Anesth Analg 2019;128:265-77. doi: 10.1213/ANE. 0000000000002812.

9. Kirkman MA, Smith M. Brain oxygenation monitoring. Anesthesiol Clin 2016;34:537-56. doi: 10.1016/j.anclin.2016.04.007.

10. Okonkwo DO, Shutter LA, Moore C, et al. Brain oxygen optimization in severe traumatic brain injury phase-II: a phase II randomized trial. Crit Care Med 2017;45:1907-14. doi: 10.1097/CCM. 0000000000002619.

11. Langer T, Santini A, Zadek F, et al. Intraoperative hypotension is not associated with postoperative cognitive dysfunction in elderly patients undergoing general anesthesia for surgery: results of a randomized controlled pilot trial. J Clin Anesth 2019;52:111-8. doi: 10.1016/j.jclinane. 2018.09.021.

12. Goettel N, Burkhart CS, Rossi A, et al. Associations between impaired cerebral blood flow autoregulation, cerebral oxygenation, and biomarkers of brain injury and postoperative cognitive dysfunction in elderly patients after major noncardiac surgery. Anesth Analg 2017; 124:934-42. doi: 10.1213/ANE.0000000000001803.

13. Erdem AF, Kayabasoglu G, Tuna AT, et al. Effect of controlled hypotension on regional cerebral 
oxygen saturation during rhinoplasty: a prospective study. J Clin Monit Comput 2016; 30:655-60. doi: 10.1007/s10877-015-9768-6.

14. Kobayashi K, Kitamura T, Kohira S, et al. Cerebral oximetry for cardiac surgery: a preoperative comparison of device characteristics and pitfalls in interpretation. J ArtifOrgans 2018;21:412-8. doi: 10.1007/s10047-018-1052-3.

15. Yoshitani K, Kawaguchi M, Ishida K, et al. Guidelines for the use of cerebral oximetry by nearinfrared spectroscopy in cardiovascular anesthesia: a report by the cerebrospinal Division of the Academic Committee of the Japanese Society of Cardiovascular Anesthesiologists (JSCVA). J Anesth 2019;33:167-96. doi: 10.1007/ s00540-019-02610-y.

16. Zheng F, Sheinberg R, Yee MS, et al. Cerebral near-infrared spectroscopy (NIRS) monitoring and neurologic outcomes in adult cardiac surgery patients and neurologic outcomes: a systematic review. Anesth Analg 2013;116. doi: 10.1213/ ANE.0b013e318277a255.

17. Lewis C, Parulkar SD, Bebawy J, et al. Cerebral neuromonitoring during cardiac surgery: critical appraisal with an emphasis on near-infrared spectroscopy. J Cardiothorac Vasc Anesth 2018;32:2313-22. doi: 10.1053/j.jvca.2018.03.032.

18. Wang Y, Li L, Wang T, et al. The efficacy of nearinfrared spectroscopy monitoring in carotid endarterectomy: a prospective, single-center, observational study. Cell Transplant 2018;28:1705. doi: 10.1177/0963689718817760.
19. Jonsson M, Lindstrom D, Wanhainen A, et al. Near infrared spectroscopy as a predictor for shunt requirement during carotid endarterectomy. Eur J Vasc Endovasc Surg 2017;53:783-91. doi: 10.1016/j.ejvs.2017.02.033.

20. Parnia S, Nasir A, Shah C, Patel R, Mani A, Richman P. A feasibility study evaluating the role of cerebral oximetry in predicting return of spontaneous circulation in cardiac arrest. Resuscitation 2012;83:982-5. doi: 10.1016/ j.resuscitation.2013.12.007

21. Ahn A, Yang J, Inigo-Santiago L, et al. A feasibility study of cerebral oximetry monitoring during the post-resuscitation period in comatose patients following cardiac arrest. Resuscitation 2014; 85:522-6. doi: 10.1016/j.resuscitation.2012.01.039

22. Yao FS, Tseng CC, Ho CY, et al. Cerebral oxygen desaturation is associated with early postoperative neuropsychological dysfunction in patients undergoing cardiac surgery. J Cardiothorac Vasc Anesth 2004;18:552-8. doi: 10.1053/j.jvca.2004.07.007

23. Colak Z, Borojevic M, Bogovic A, et al. Influence of intraoperative cerebral oximetry monitoring on neurocognitive function after coronary artery bypass surgery: a randomized, prospective study. Eur J Cardiothorac Surg 2014;47:447-54. doi: 10.1093/ejcts/ezu193. 